\title{
Congenital muscular dystrophy with cerebellar involvement
}

INSERM

\section{Source}

INSERM. (1999). Orphanet: an online rare disease and orphan drug data base. Congenital muscular dystrophy with cerebellar involvement. ORPHA:370959

Congenital muscular dystrophy with cerebellar involvement is a rare, congenital muscular dystrophy due to dystroglycanopathy characterized by proximal muscule weakness with a tendency for muscle hypertrophy and pseudohypertrophy, variable cog nitive impairment, microcephaly, cerebellar hypoplasia with or without cysts, and other structural brain anomalies. 